\title{
Kinetics of soil cadmium desorption under simulated acid rain
}

\author{
Dai-Zhang Wang ${ }^{\mathrm{a}, \mathrm{b}}$, Xin Jiang ${ }^{\mathrm{b}}$, Wei Rao ${ }^{\mathrm{a}}$, Ji-Zheng $\mathrm{He}^{\mathrm{c}, *}$ \\ ${ }^{a}$ College of Resources and Environment, Henan Agricultural University, Zhengzhou 450002, China \\ ${ }^{\mathrm{b}}$ Institute of Soil Science, Chinese Academy of Sciences, Nanjing 210008, China \\ ${ }^{\mathrm{c}}$ Research Centre for Eco-environmental Sciences, Chinese Academy of Sciences, Beijing 100085, China
}

\section{A R T I C L E I N F O}

\section{Article history:}

Received 7 April 2008

Received in revised form 2 February 2009

Accepted 4 March 2009

Available online 11 April 2009

\section{Keywords:}

Cadmium desorption

Kinetics

Ecological risk

Acid rain

China

\begin{abstract}
A B S T R A C T
Soil acidification can result in the release of heavy metals stabilized by soil components into soil solution, and therefore it causes ecological risk. The kinetics of Cd desorption from two Chinese soils (ultisol and oxisol) distributed in the acid rain sensitive areas of southern China, were studied using a flow-stirred method under simulated acid rain conditions. Cd desorption was well described by the first-order kinetic equation. Percentages of Cd desorbed were $80-99 \%$ in ultisol and $25-28 \%$ in oxisol, respectively. Cd desorption, regarded as a heterogeneous diffusion in soils, could be also fitted by the Elovich equation. The desorption process could be divided into a fast reaction and a slow reaction, which were corresponded to the exchangeable and the specific sorbed $\mathrm{Cd}$, respectively. The obtained results are essential to understand the process of heavy metal release under acid deposition conditions and to evaluate the ecological risk of acid deposition in those acid rain sensitive areas of China.
\end{abstract}

(c) 2009 Elsevier B.V. All rights reserved.

\section{Introduction}

Large amounts of heavy metals have accumulated in agricultural soils in China due to industrialized development in rural and urban regions during recent decades. Among the heavy metals, cadmium (Cd) contaminated agricultural land received special attentions and increased quickly in recent years in China (Chen et al., 2000). Cd sources in agricultural fields were strongly affected by anthropogenic activities, such as industrial wastes, mine activities, irrigation by wastewater, application of sewage sludge and $\mathrm{P}$ fertilizers, and atmospheric deposition (Naidu et al., 1997; Chen et al., 2000).

The reactivity, mobility, bioavailability, and toxicity of Cd are strongly affected by sorption and desorption processes, which depend on the metal partitions between solid phases and the soil solution. The concentrations of heavy metals in soil solution are most likely governed by sorption and desorption of the heavy metal with different soil constituents, such as various hydrous oxides, clay minerals and organic matter (OM) (Ainsworth et al., 1994). Other factors such as soil $\mathrm{pH}$, temperature, ionic strength and time could also play important roles in Cd sorption-desorption reactions (Ainsworth et al., 1994; Gray et al., 1998; Eick et al., 1999).

Previous studies indicated that Cd desorption was as important as its sorption. However, desorption behavior of a metal ion usually

\footnotetext{
* Corresponding author. Tel.: +86106284 9788; fax: +861062923563.

E-mail address: jzhe@rcees.ac.cn (J.-Z. He).
}

differs from its sorption and lead to a lack of coincidence in the experimentally obtained sorption and desorption conditions (Shirvani et al., 2006). Desorption of heavy metals from solid surfaces is also strongly $\mathrm{pH}$ dependent, which is an important process regulating metal concentrations in soil solution. The desorption efficiency was greater than $80 \%$ for $\mathrm{Ni}(\mathrm{II}), \mathrm{Cu}(\mathrm{II}), \mathrm{Zn}$ (II) and Cd (II) on ferrihydrite in $30 \mathrm{~min}$ at pH 4.5 (Schultz et al., 1987). Cd release rates were very low at $\mathrm{pH}$ above 5.0 and increased exponentially as $\mathrm{pH}$ decreased below 4.5 for afforestation of cultivated soil (Strobel et al., 2001). Those results were mostly investigated by equilibrium techniques at different $\mathrm{pH}$ conditions. However, the kinetic processes of Cd desorption influenced by $\mathrm{pH}$ are still poorly understood in variable charged soils.

Acid rain is recognized as one of the major environmental issues in recent decades due to rapid economic development in China (Larssen et al., 1999). Some researchers reported that acid rain with $\mathrm{pH}$ from 3.0 to $\mathrm{pH} 4.5$ usually occurred in large areas mainly south of the Yangtze River, especially in the suburbs of industrial cities (Wang and Ding, 1997). It caused deterioration of ecosystem and soil fertility in tropical and subtropical areas, such as accelerating soil acidification, resulting in the activation of aluminum $(\mathrm{Al})$ and toxic heavy metals and thus increasing their ecological risk (Yu, 1997; Liao et al., 1998; Xu and Ji, 2001). However, the influence of acid rain on Cd desorption from the soils of the acid rain sensitive area in southern China received very limited attention.

Traditionally, desorption studies were performed using batch methods, which could not reflect naturally occurring processes due to leaching or plant uptake over time. The process of $\mathrm{Cd}$ desorption could be controlled mainly by time-dependent, rather 
than equilibrium reactions. In methodology, the flow technique combines some of the favorable aspects of both batch and miscible-displacement techniques (Bar-Tal et al., 1990). It reflects mechanisms and reaction rates of ionic nutrients in soils (Spark et al., 1995). The purpose of this study was to measure the rate parameters of Cd desorption kinetics by using an improved stirred-flow technique. The findings would improve understanding of $\mathrm{Cd}$ desorption mechanisms from variable charge soils by simulated acid rain in order to provide information for evaluation of Cd potential toxicity and ecological risk in acid rain areas of China.

\section{Materials and methods}

\subsection{Soil samples}

An oxisol (located at $110^{\circ} 10^{\prime} \mathrm{E}, 20^{\circ} 20^{\prime} \mathrm{N}$, Xuwen, Guangdong province) and an ultisol (located at $116^{\circ} 56^{\prime} \mathrm{E}, 28^{\circ} 13^{\prime} \mathrm{N}$, Yingtan, Jiangxi province) were collected from acid rain sensitive area in southern China. The samples were air-dried and passed through a 60-mesh sieve. The oxisol was derived from basalt and the dominant clay components were kaolinite and $\mathrm{Al}$ and iron $(\mathrm{Fe})$ oxides. The ultisol was derived from the Quaternary red earth and the clay minerals included kaolinite, illite and vermiculite. Basic soil properties were $\mathrm{pH}\left(\mathrm{H}_{2} \mathrm{O}\right) 5.61, \mathrm{pH}(\mathrm{KCl}) 5.40$, soil organic matter (SOM) $5.8 \mathrm{~g} / \mathrm{kg}$, clay content $640.0 \mathrm{~g} / \mathrm{kg}$ and $\mathrm{CEC}_{\mathrm{pH} 7.0} 7.15 \mathrm{cmol} / \mathrm{kg}$ for the oxisol; and $\mathrm{pH}\left(\mathrm{H}_{2} \mathrm{O}\right) 4.57, \mathrm{pH}(\mathrm{KCl})$ 3.81 , SOM $9.1 \mathrm{~g} / \mathrm{kg}$, clay $515.4 \mathrm{~g} / \mathrm{kg}$ and $\mathrm{CEC}_{\mathrm{pH} 7.0} 11.2 \mathrm{cmol} / \mathrm{kg}$ for the ultisol, respectively. The $\mathrm{pH}$ was determined in distilled water and in $1 \mathrm{M} \mathrm{KCl}$ with a 1:2.5 soil:solution ratio, the clay contents by the pipette method, Fe oxides content (Fed) by dithionite citrate bicarbonate extraction, organic matter by the classical method of dichromate oxidation, and soil cation exchange capacity $\left(\mathrm{CEC}_{\mathrm{pH} \text {.0. }}\right)$ by the conventional $\mathrm{NH}_{4} \mathrm{Ac}$ method. The point of zero charge (ZPC) of the samples, by STPT method (Sakurai et al., 1989), was 4.42 for oxisol and 3.12 for ultisol. These two soils had high contents of clay and total Fe oxides, and low pH, low organic matter and low CEC, clearly identified as variable charge soils.

\subsection{Simulated acid rain}

$\mathrm{SO}_{4}{ }^{2-}$ and $\mathrm{NO}_{3}{ }^{-}$in the acid rain of southern China were 90-140 and 26-70 $\mu \mathrm{M}$ from 1986 to 1993, respectively (Wang and Ding, 1997). According to this chemical composition of the rainfall in southern China, the simulated acid rains in this experiment were made of a $\mathrm{H}_{2} \mathrm{SO}_{4}$ to $\mathrm{HNO}_{3}$ mole ratio of $4: 1$ with $\mathrm{pH} 3.5$ and $\mathrm{pH} 4.5$.

\subsection{Cd sorption}

Batch sorption studies were performed at $25^{\circ} \mathrm{C}$ to obtain the equilibrium isotherms in triplicates. A series of $100 \mathrm{ml}$ plastic centrifuge tubes were filled each with $50 \mathrm{ml}$ of $\mathrm{Cd}$ solution of varying concentrations $(0.1,0.2,0.4,0.6,0.8$, and $1.0 \mathrm{mM})$ in $0.01 \mathrm{M}$ $\mathrm{KNO}_{3}$ background electrolyte with a $1: 10$ soil to solution ratio. The samples were added into each tubes and shaken for $2 \mathrm{~h}$ in a horizontal reciprocating shaker, left for $24 \mathrm{~h}$. Supernatants were centrifuged for $10 \mathrm{~min}$ at $4500 \mathrm{rpm}$ and filtrated with $0.45 \mu \mathrm{m}$ filter paper. The residual soils were collected and rinsed with absolute alcohol. These samples were dried to be prepared to perform the kinetics of $\mathrm{Cd}$ desorption. The supernatants were analyzed for Cd by flame atomic absorption spectroscopy (AAS vario 6, Analytic Jena, Germany) and Cd concentration retained in the adsorbent phase $(\mathrm{mmol} / \mathrm{kg})$ was obtained. The sorption data were fitted to Langmuir and Freundlich equation (Harter and Baker, 1977; Sposito, 1980).

\subsection{Kinetics of Cd desorption}

A continuous-flow-stirred reactor technique, modified from Shiowatana et al. (2001), was used to determine the kinetics of Cd desorption under acidic solution. The basic components of this kinetic device included acidic solution, peristaltic pump, magnetic stirrer, flow-stirred reactor and fraction collectors as shown in Fig. 1.

Cd desorption was carried out using above sorbed Cd samples. Each treatment of desorption kinetics was coded by according to effluent $\mathrm{pH}$ and added $\mathrm{Cd}$ concentrations $(\mathrm{mM})$ in equilibrium experiment, such as pH4.5 (0.6). Each $1.0 \mathrm{~g}$ of soil samples by $\mathrm{Cd}$ sorbed was placed into the reactor and then assembled the pieces of the device. All experiments were controlled at $25^{\circ} \mathrm{C}$ in duplicate. The simulated acid rain was passed through a silicone tube of $2-\mathrm{mm}$ in inner diameter into the reactor to sufficiently mix with samples using a peristaltic pump. The reactor and its cover were made of organic glass to have a capacity of approximately $10 \mathrm{ml}$. The outlet of the reactor was furnished at upside with a filter $(0.45 \mu \mathrm{m}$ microfibre filter, $30 \mathrm{~mm}$ in diameter) to allow solution to automatically flow through at inner pressure with $1.0 \mathrm{ml} / \mathrm{min}$ flow rate. The effluent was collected in constant volume with an auto-digital control fraction collector at designedmade time when the first drop flowed out. Influent volume was collected. Cd concentration and $\mathrm{pH}$ of the effluent were analyzed.

\section{Results}

\subsection{The equilibrium concentrations and the amounts of $C d$ sorption}

The amounts of $\mathrm{Cd}$ sorbed in the soils increased with increasing $\mathrm{Cd}$ concentrations in the equilibrium solution. The corresponding parameters were modeled by the Langmuir and Freundlich equations, which the determination coefficients $\left(R^{2}\right)$ were 0.922 and 0.998 , respectively.

Based on the Langmuir equation, the maximum sorption capacity $\left(Q^{\circ}\right)$ was 9.23 and $3.67 \mathrm{mmol} / \mathrm{kg}$ for the oxisol and ultisol, respectively. The corresponding $b$ values, related to the free energy of sorption and the affinity of the binding sites, were 0.108 and $0.324 \mathrm{l} / \mathrm{mmol}$, respectively. Unlike the Langmuir model, the differences in sorption enthalpy between different types of sites were accounted for by the Freundlich model. $K_{f}$ values, the relative sorption capacity for $\mathrm{Cd}$, were 9.46 and $3.06 \mathrm{mmol} / \mathrm{kg}$ for the oxisol and ultisol, respectively. $1 / n$ values, the surface affinity to $\mathrm{Cd}$ had the obvious difference from the energy sites of Cd sorption, were 0.439 and 0.509 for the oxisol and ultisol, respectively. The relative sorption capacity had the same order as $Q^{\circ}$ value. The difference of amounts of sorbed $\mathrm{Cd}$ could be related to the different $\mathrm{pH}$ at the equilibrium in the soils. The solution $\mathrm{pH}$ values at equilibrium were from $\mathrm{pH} 5.6$ to $\mathrm{pH} 5.2$ in the oxisol and from $\mathrm{pH} 4.8$ to $\mathrm{pH} 4.4$ in the ultisol with added $\mathrm{Cd}$ concentrations, respectively. The

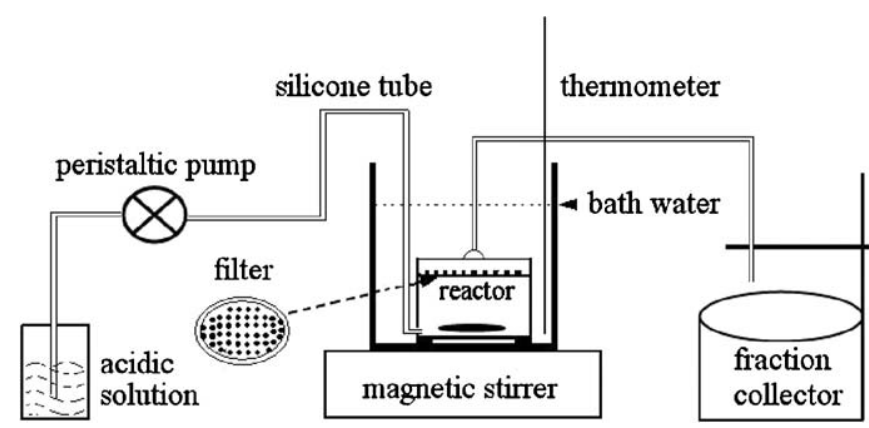

Fig. 1. Sketch of a continuous-flow-stirred kinetic device used in this study. 

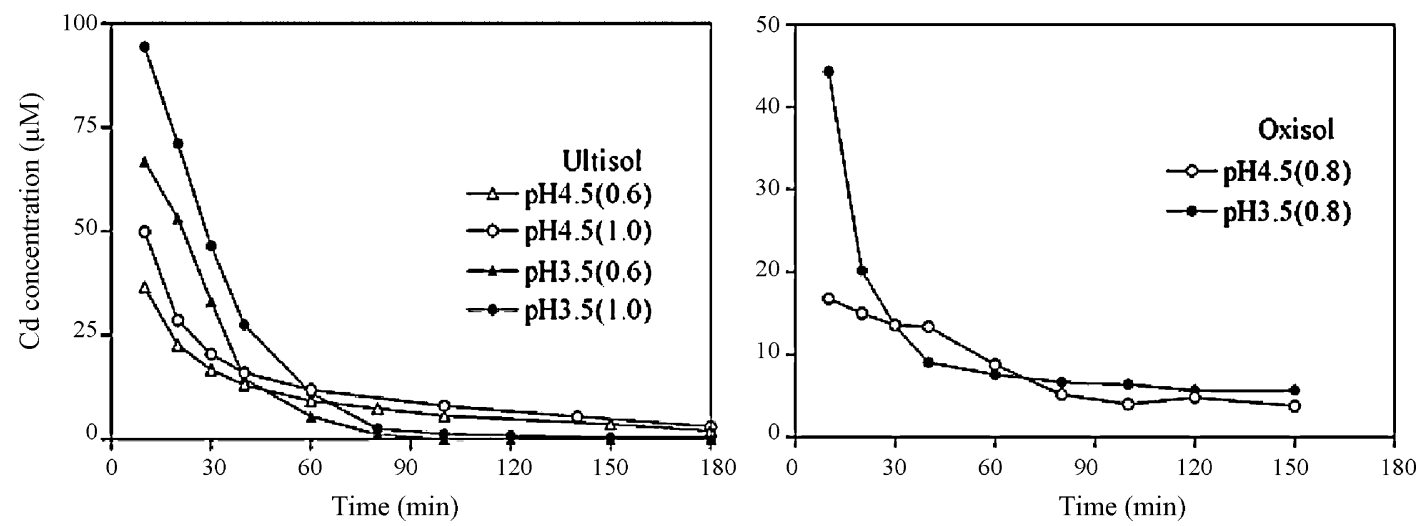

Fig. 2. The relationship between the concentrations vs. the time for Cd desorption from the ultisol and oxisol.

percentage of Cd sorption was about $60-70 \%$ in the oxisol and $25-$ $30 \%$ in the ultisol at high $\mathrm{Cd}$ concentrations. The different $\mathrm{pH}$ values at equilibrium solution could reflect the species of sorbed $\mathrm{Cd}$ onto solid surface.

\subsection{The reactive time and the concentrations of $\mathrm{Cd}$ desorption}

The effluent volume was invariably collected at $1.0 \mathrm{ml} / \mathrm{min}$ of the velocity of flow using automatic collector in this experiment. It could be reflected that the concentration of $\mathrm{Cd}$ desorption changed with the time. The effluent concentrations of Cd decreased sharply during 0-60 min as shown in Fig. 2. The experimental data showed that the concentrations of $\mathrm{Cd}$ desorption are different from between the capacity of sorbed $\mathrm{Cd}$ and the influent $\mathrm{pH}$. The amounts of desorbed $\mathrm{Cd}$ were $36.5,49.9,66.8$ and $94.4 \mu \mathrm{M}$ for pH4.5 (0.6), pH4.5 (1.0), pH3.5 (0.6) and pH3.5 (1.0) treatments in the ultisol, 16.8 and $44.3 \mu \mathrm{M}$ for $\mathrm{pH} 4.5(0.8)$ and $\mathrm{pH} 3.5(0.8)$ treatments in the oxisol during 0-10 $\mathrm{min}$, and then dropped to 5$10 \mu \mathrm{M}$ at $60 \mathrm{~min}$. It could be shown further that the desorption process nearly completed during $0-60 \mathrm{~min}$ in the obvious fast reaction stage, and then closed to pseudo-equilibrium state. Therefore, the kinetics of $\mathrm{Cd}$ desorption from the soil surface had two clear stages: a very rapid stage during 0-60 min and then a very slow stage.

\subsection{Effluent $\mathrm{pH}$ change during $\mathrm{Cd}$ desorption process}

The effluent $\mathrm{pH}$ changes in $\mathrm{Cd}$ desorption process was shown in Fig. 3. As to the influent $\mathrm{pH} 3.5$, the effluent $\mathrm{pH}$ decreased from $\mathrm{pH}$ 4.2 moderately down to $\mathrm{pH} 3.7$ in $80 \mathrm{~min}$ in the ultisol, and fluctuated at $\mathrm{pH} 6.0$ in the oxisol. As to the influent $\mathrm{pH} 4.5$, the effluent $\mathrm{pH}$ fluctuated at $\mathrm{pH} 5.0$ in the ultisol, and increased from
pH 6.2 up to pH 7.2 in 40 min and then decreased to pH 6.5 in the oxisol. This results indicated that it had a great quantity of $\mathrm{H}^{+}$ consumption in the two soils during the desorption process. It was observed that the effluent $\mathrm{pH}$ values were above 7.0 in the oxisol, which could be deduced that $\mathrm{OH}^{-}$released from the soils during the process of $\mathrm{Cd}$ desorption. It was also noted that $\mathrm{H}^{+}$ consumption could have the fast reactive process in $80 \mathrm{~min}$ and followed by the slow reaction for $\mathrm{pH} 3.5$ in the ultisol.

\subsection{The kinetic equations of Cd desorption}

The accumulative amounts of Cd desorption were calculated according to influent volume and $\mathrm{Cd}$ concentration. Several kinetics were used to fit the relationship between desorbed amounts and time, such as

the first order kinetics : $\ln \left(1-\frac{q_{t}}{q_{\infty}}\right)=-k^{\prime} t$

Elovich equation : $q_{t}=a+b \ln t$

where $q_{t}$ is the amount desorbed in any time, $q_{\infty}$ is the maximum amount desorbed, $t$ is time, $a$ and $b$ are the parameters of the equations. The major parameters of kinetics were in Table 1.

By using the first-order kinetics to fit the data of $\mathrm{Cd}$ desorption, the determination coefficient $\left(R^{2}\right)$ was more than 0.99 . The average value of $k^{\prime}$ increased from 0.013 to 0.023 in the oxisol and from 0.021 to 0.056 in the ultisol as the influent $\mathrm{pH}$ decreased from $\mathrm{pH} 4.5$ to $\mathrm{pH} 3.5$, respectively. The $k^{\prime}$ value increased with an increase in the effluent acidity, which implied the solution acidity enhanced the rate of Cd desorption. The bigger the $k^{\prime}$ value was, the quicker the fast reactive stage was. In order to compare the
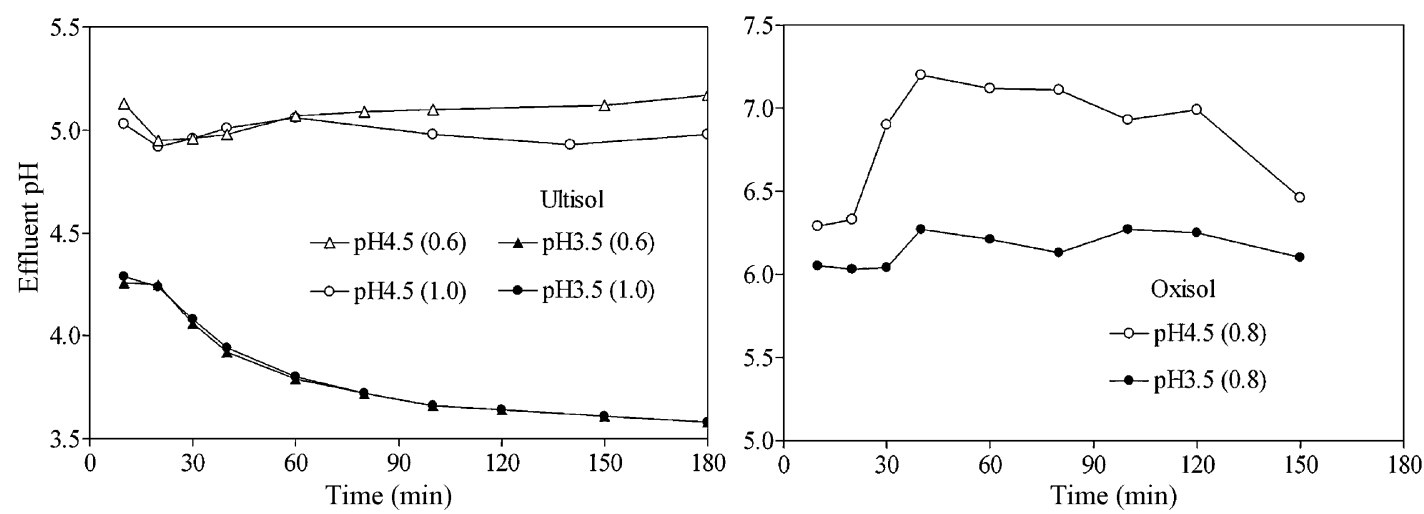

Fig. 3. Change of effluent $\mathrm{pH}$ in $\mathrm{Cd}$ desorption process from the ultisol and oxisol. 
Table 1

Major parameters of the kinetics of Cd desorption from two soils.

\begin{tabular}{|c|c|c|c|c|c|c|c|c|}
\hline \multirow[t]{2}{*}{ Soils } & \multirow[t]{2}{*}{ Treatment code } & \multirow[t]{2}{*}{$q_{e}$} & \multirow[t]{2}{*}{$\left(q_{\infty} / q_{e}\right) \times 100$} & \multicolumn{3}{|c|}{ The first-order kinetics, $\ln \left(1-q_{t} / q_{\infty}\right)=k^{\prime} t$} & \multicolumn{2}{|c|}{$\begin{array}{l}\text { Elovich equation, } \\
q_{t}=a+b \ln t\end{array}$} \\
\hline & & & & $q_{\infty}$ & $k^{\prime}$ & $R^{2}$ & $b$ & $R^{2}$ \\
\hline \multirow[t]{4}{*}{ Ultisol } & $\mathrm{pH} 4.5(0.6)$ & 1.97 & 84.3 & 1.66 & 0.021 & 0.992 & 0.46 & 0.994 \\
\hline & $\mathrm{pH} 4.5(1.0)$ & 2.84 & 75.7 & 2.15 & 0.020 & 0.992 & 0.57 & 0.995 \\
\hline & $\mathrm{pH} 3.5(0.6)$ & 1.97 & 99.0 & 1.95 & 0.056 & 0.996 & 0.77 & 0.996 \\
\hline & $\mathrm{pH} 3.5(1.0)$ & 2.84 & 99.6 & 2.83 & 0.048 & 0.998 & 1.08 & 0.999 \\
\hline \multirow[t]{2}{*}{ Oxisol } & $\mathrm{pH} 4.5(0.8)$ & 5.62 & 25.2 & 1.40 & 0.013 & 0.998 & 0.41 & 0.980 \\
\hline & $\mathrm{pH} 3.5(0.8)$ & 5.62 & 28.1 & 1.58 & 0.023 & 0.966 & 0.43 & 0.972 \\
\hline
\end{tabular}

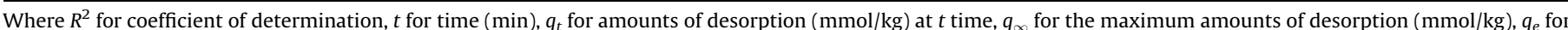

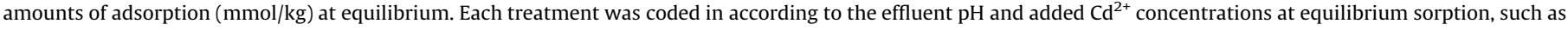
pH4.5 (0.6).

efficiency of Cd desorption by the simulated acid rain from the soils, the percentage of Cd desorption was defined as the ratio of the theoretical desorption amounts and actual sorption amounts. The percentage of Cd desorption increased from $80 \%$ to $99 \%$ in the ultisol and from $25 \%$ to $28 \%$ in the oxisol as the influent $\mathrm{pH}$ from $\mathrm{pH} 4.5$ to $\mathrm{pH} 3.5$, respectively. It implied that $\mathrm{Cd}$ desorption was nearly completely reversible in the ultisol, but mostly not reversible in the oxilsol.

In this experiment, the data by fitting Elovich equation indicated that the relationshop between $q$ and $\ln t$ was expressed by two linear equations, which was consistent with the fast reaction and the slow reaction of Cd desprption. The determining coefficient $\left(R^{2}\right)$ of the linear equation was $0.972-0.998$ in the fast reaction. From the Elovich equation, the rate equation at Cd releasing was obtained by $\mathrm{d} q / \mathrm{d} t=b / t$. The $b$ value was used to compare the relative rate of $\mathrm{Cd}$ releasing and was relative to the diffusion rate of $\mathrm{Cd}$ from solid phase to the bulk solution. The $b$ values in the fast reactive stage averaged 0.51 and 0.92 for $\mathrm{pH} 4.5$ and $\mathrm{pH} 3.5$ in the ultisol, 0.32 and 0.34 for pH4.5 (0.8) and pH3.5 (0.8) in the oxisol. The bigger the $b$ value was, the faster the relative rate of $\mathrm{Cd}$ diffusion was.

\section{Discussion}

\subsection{The meaning of kinetics of Cd desorption in the soils}

In the equilibrium sorption experiments, the species of $\mathrm{Cd}$ in solution had made an influence on the speciation of $\mathrm{Cd}$ in solid phase which was relative to the degree of $\mathrm{Cd}$ desorption. The distribution of $\mathrm{Cd}$ species in solution were $\mathrm{Cd}^{2+}, \mathrm{Cd}(\mathrm{OH})^{+}$at $\mathrm{pH}<6.0$ and $\mathrm{Cd}^{2+}, \mathrm{Cd}(\mathrm{OH})^{+}, \mathrm{Cd}(\mathrm{OH})_{2}$ at $\mathrm{pH}$ 6.0-7.0 according to a function of $\mathrm{pH}$ in the solution. The sorption reactions at the solid phase interface involved interaction with deprotonated surface hydroxyl groups to form inner- and outer-sphere complexes which the $\mathrm{pH}_{\mathrm{zpc}}$ value was considered (Schindler et al., 1987; Randall et al., 1999). Firstly, acid-base reactions at the mineral surface can be expressed as

$$
\begin{aligned}
& \mathrm{SOH} \leftrightarrow \mathrm{SO}^{-}+\mathrm{H}^{+}, \quad \text { pHofthesolution }>\mathrm{pH}_{\mathrm{zpc}} \\
& \mathrm{SOH}+\mathrm{H}^{+} \leftrightarrow \mathrm{SOH}_{2}^{+}, \quad \text { pHofthesolution }<\mathrm{pH}_{\mathrm{zpc}}
\end{aligned}
$$

The selected oxisol and ultisol, called as variable charge soils, were distributed widely in the vast tropical and subtropical regions of southern China. As the solution $\mathrm{pH}$ at the equilibrium sorption of $\mathrm{Cd}$ was above the $\mathrm{pH}_{\mathrm{zpc}}$ of soils, the surface reactions of $\mathrm{Cd}$ sorption were assumed to form SOCd ${ }^{+}, \mathrm{SOH} \cdots \mathrm{Cd}$ and $\left(\mathrm{X}_{2}\right)^{2-} \ldots \mathrm{Cd}^{2+}$.

Where $\mathrm{SOH}, \mathrm{SOH}_{2}{ }^{+}$and $\mathrm{SO}^{-}$represent a neutral, protonated and deprotonated surface sites respectively, and $\mathrm{X}^{-}$represents a permanent negatively charged site. $\mathrm{SOCd}^{+}$depicts the formation of an inner-sphere $\mathrm{Cd}$ surface complex, while $\mathrm{SOH} \ldots \mathrm{Cd}$ and $\left(\mathrm{X}_{2}\right)^{2-} \ldots \mathrm{Cd}^{2+}$ represent the formation of outer-sphere surface complexes.
Gunneriusson (1994) thought that $\mathrm{SOH} \cdots \mathrm{Cd}^{2+}$ was the major sorbed species below $\mathrm{pH} 6, \mathrm{SOCd}^{+}$dominated at $\mathrm{pH}$ 6-8. From $\mathrm{pH}$ values at equilibrium sorption, the species of $\mathrm{Cd}$ sorbed could be mainly $\mathrm{SOCd}^{+}$, $\mathrm{SOH} \cdots \mathrm{Cd}^{2+}$ and $\left(\mathrm{X}_{2}\right)^{2-} \ldots \mathrm{Cd}^{2+}$ in the oxisol and ultisol. At low $\mathrm{pH}, \mathrm{H}^{+}$could successfully exchange $\mathrm{Cd}$ from sites of $\mathrm{SOH} \cdots \mathrm{Cd}^{2+}$ and $\left(\mathrm{X}_{2}\right)^{2-} \ldots \mathrm{Cd}^{2+}$. By the experimental results, it may be reasoned that the easily desorbed Cd could be $\mathrm{SOH} \cdots \mathrm{Cd}^{2+}$ and $\left(\mathrm{X}_{2}\right)^{2-} \ldots \mathrm{Cd}^{2+}$, and the difficulty sorbed Cd could be $\mathrm{SOCd}^{+}$in the form of the inner-sphere complexation.

The kinetic curves of $\mathrm{Cd}$ desorption can be divided into two stages in the acidic solution. The first stage located within the initial $60 \mathrm{~min}$, at which the release rate of Cd was very fast and the released Cd dominantly originated from exchangeable $\mathrm{SOH} \cdots \mathrm{Cd}^{2+}$ and $\left(\mathrm{X}_{2}\right)^{2} \cdots \mathrm{Cd}^{2+}$. The slow stage was from specific sorption of SOCd $^{+}$. Sparks (1987) reported the suitability of the Elovich equation to describe the diffusion mechanism of slow reaction and it could explain various energetics of the chemisorption. The heterogeneous active sites in surface exhibited different activation energies for chemisorption (Teng and Hsieh, 1999). Taylor et al. (1995) successfully applied the Elovich equation to the sorption of zinc ions in soils. Juang and Chen (1997) also used the Elovich equation in the sorption of metals on solvent impregnated resins. Our results indicated that energetic distributions of surface were heterogeneous, which were consistent with equilibrium isotherm of $\mathrm{Cd}$ sorption by using the Freundlich equation. It indicated that the process of Cd desorption could be controlled by the different rate mechanisms involving in the system $\mathrm{pH}$.

\subsection{The infulence of $\mathrm{pH}$ on $\mathrm{Cd}$ desorption}

The rate of $\mathrm{Cd}$ desorption increased with a decrease of the influent $\mathrm{pH}$ value from 4.5 to 3.5 by the estimations of the rate constants ( $k^{\prime}$ and $b$ values). $\mathrm{H}^{+}$ion could be sorbed in the bonding sites of mineral surface, which will lead to the increasing amount of Cd desorption, such as following reactions:

$$
\begin{aligned}
& \mathrm{SOH} \cdots \mathrm{Cd}^{2+}+\mathrm{H}^{+} \leftrightarrow \mathrm{SOH}_{2}++\mathrm{Cd}^{2+} \\
& \mathrm{SOCd}^{+}+\mathrm{H}^{+} \leftrightarrow \mathrm{SOH}+\mathrm{Cd}^{2+}
\end{aligned}
$$

The different affinity of the bonding sites to Cd may cause the difference in the rates and amounts of $\mathrm{Cd}$ desorbed. Furthermore, the surface protonation in soils promoted dissolution of Fe in acid solution to increase Cd desorption (Eq. (7)):

$\mathrm{Fe}-\mathrm{OH}+\mathrm{H}^{+} \leftrightarrow \mathrm{Fe}-\mathrm{OH}_{2}{ }^{+} \leftrightarrow$ dissolution $\left(\mathrm{Fe}^{3+}\right)$

The Cd desorption in the ultisol and oxisol could be dependent on the composition of the clay minerals, $\mathrm{pH}$ and anion ions of acid solution. While releasing kinetics of metals were governed by environmental conditions such as $\mathrm{pH}$, the effluent $\mathrm{pH}$, about 6.07.3 in oxisol and about 3.5-5.0 in ultisol, will also have an influence 
on $\mathrm{Cd}$ desorption. It indicates the consuming processes of $\mathrm{H}^{+}$in the oxisol differed from that in the utlisol. $\mathrm{H}^{+}$ion consumption is an important factor which affects the solution $\mathrm{pH}$. Firstly $\mathrm{H}^{+}$ions could only exchange some metal cations, but the surface hydroxyl groups attached to $\mathrm{Fe}$ or $\mathrm{Al}$ atoms could accept protons from solution, resulting in an increase in positive surface charges, called as the protonation in mineral surface (Zhang et al., 1991; Zhu et al., 2005). The protonation is a very fast reaction at the initial stage and depended on the amounts and properties of $\mathrm{Fe}-\mathrm{OH}$. Secondly, the specific adsorption of $\mathrm{SO}_{4}{ }^{2-}$ on the surface of the minerals could release $\mathrm{OH}^{-}$for neutralizing $\mathrm{H}^{+}$in the solution. This mainly depends on the content of ferric oxides in the two soils (Yu, 1997). The mechanism was as follows:

$\left.\left.\mathrm{Fe}\right|_{-\mathrm{OH}_{2}} ^{-\mathrm{OH}_{2}}\right|^{0}+\left.\left.\mathrm{SO}_{4}^{2-} \rightarrow \mathrm{Fe}\right|_{-\mathrm{SO}_{4}} ^{-\mathrm{OH}_{2}}\right|^{-}+\mathrm{OH}^{-}$

The obvious difference of surface properties between in the oxisol and in the ultisol has different influence on Cd desorption in short time under simulated acid rain containing $\mathrm{SO}_{4}{ }^{2-}$. If $\mathrm{OH}^{-}$ release and surface protonation were very fast, it could consume a large quantity of $\mathrm{H}^{+}$to decrease the amounts of $\mathrm{Cd}$ desorption.

\subsection{Cd desorption and ecological risk}

The bioavailability, toxicity and mobility of heavy metals in soils are largely determined by their kinetic processes between solution and solid phases. Factors such as $\mathrm{pH}$ may play a dominant role in controlling the nature of the interactions between metals and the soil surfaces (Zhang et al., 2006). The rates of metal release from the solid phase provide the basic information for describing the kinetic processes.

This research shows that $\mathrm{Cd}$ releases so quickly from the solid phase to the solution. The $k^{\prime}$ and $b$ values increased about one time for $\mathrm{pH} 3.5$ more than for $\mathrm{pH} 4.5$ in the ultisol. The effluent $\mathrm{pH}$ values were 4.2-5.0 and the percentage of Cd desorption was $80-99 \%$. Cd sorption-desorption process is approximately reversible by the influence of the solution $\mathrm{pH}$. As the soil $\mathrm{pH}$ decreases, metals are desorbed from soil particles, and enter the soil solution and become more mobile ( $\mathrm{Li}$ and $\mathrm{Wu}, 1999$ ). In the oxisol, the slightly faster rates of release were observed. The effluent $\mathrm{pH}$ values were $6.0-7.2$, and the percentage of Cd desorption was $25-28 \%$. As compared to other toxic heavy metals, $\mathrm{Cd}$ is exceptionally soluble in soil. $\mathrm{Cd}$ is relatively mobile between the $\mathrm{pH}$ of 4.2 and 6.6, and only moderately mobile between the $\mathrm{pH}$ of 6.7 and 8.8 (Schmitt and Sticher, 1991). Below pH 5, dissolved Cd concentration increased rapidly due to $\mathrm{pH}$ dependent desorption from the soil surface. As for a soil, fluxes of metals from the stirred chamber are similar to fluxes to plants. Rates of metal release from the solid phase may limit the rate of $\mathrm{Cd}$ supply to plants in these soils. The soluble capacity of toxic metals will significantly increase if the soil solution is acidified by acid rain. The potential threat of $\mathrm{Cd}$ under acid rain conditions should receive attention in the acid rain sensitive areas of China.

\section{Conclusion}

The processes of Cd desorption from the ultisol and oxisol consisted of a fast reaction and a slow reaction, which were corresponded to exchangeable and specific Cd adsorption, respectively. As the energy distributions of sites of sorption in the soils were heterogeneous, the bonding sites of edge hydroxyl had the different affinity to the sorbed $\mathrm{Cd}$, which led to the difference of the rate and amount of Cd desorption. Cd desorption could be well described by the first-order kinetics and Elvoich equation. The different mechanisms of Cd sorptiondesorption could be related to the solution $\mathrm{pH}$ and the properties of the soils. The increase of effluent $\mathrm{pH}$ reflected the different ways of $\mathrm{H}^{+}$consumption which exchanged with metal ions, increased the positive charge as protonation, and neutralized $\mathrm{OH}^{-}$released by the specific sorption of $\mathrm{SO}_{4}{ }^{2-}$ in the acid rain. $\mathrm{Cd}$ release under simulated acid rain could significantly increase its ecological risk.

\section{Acknowledgment}

The financial support from the Natural Science Foundation of China (Grant Nos. 40325001, 50621804) is acknowledged.

\section{References}

Ainsworth, C.C., Pilon, J.L., Gassman, P.L., van der Sluys, W.G., 1994. Cobalt, cadmium, and lead sorption to hydrous iron oxide: residence time effect. Soil Science Society of America Journal 58, 1615-1623.

Bar-Tal, A., Sparks, D.L., Pesek, J.D., Feigenbaum, S., 1990. Analyses of adsorption kinetics using a stirred-flow chamber. I. Theory and critical tests. Soil Science Society of America Journal 54, 1273-1278.

Chen, H.M., Zheng, C.R., Tu, C., Shen, Z.G., 2000. Chemical methods and phytoremediation of soil contaminated with heavy metals. Chemosphere 41, 229-234.

Eick, M.J., Peak, J.D., Brady, P.V., Pesek, J.D., 1999. Kinetics of lead adsorption/ desorption on goethite: residence time effect. Soil Science 164, 28-39.

Gray, C.W., McLaren, R.G., Roberts, A.H.C., Condron, L.M., 1998. Sorption and desorption of cadmium from some New Zealand soils: effect of $\mathrm{pH}$ and contact time. Australian Journal of Soil Research 36, 199-216.

Gunneriusson, L., 1994. Composition and stability of Cd (II)-chloro and -hydroxo complexes at the goethite $(\alpha-\mathrm{FeOOH}) /$ water interface. Journal of Colloid and Interface Science 163, 484-492.

Harter, R.D., Baker, D.E., 1977. Applications and misapplications of the Langmuir equation to soil adsorption phenomena. Soil Science Society of America Journal 41, 1077-1080.

Juang, R.S., Chen, M.L., 1997. Application of the Elovich equation to the kinetics of metal sorption with solvent-impregnated resins. Industrial \& Engineering Chemistry Research 36, 813-820.

Larssen, T., Seip, H.M., Semb, A., Mulder, J., Muniz, I.P., Vogt, R.D., Lydersen, E., Angell, V., Dagang, T., Eilertsen, O., 1999. Acid deposition and its effects in China: an overview. Environmental Science and Pollution 2, 9-24.

Li, L., Wu, G., 1999. Numerical simulation of transport of four heavy metals in kaolinite clay. Journal of Environmental Engineering 125, 314-324.

Liao, B., Seip, H.M., Larssen, T., 1998. Response of five Chinese forest soils to acidic inputs: batch experiment. Geoderma 86, 295-316.

Naidu, R., Kookana, R.S., Sumner, M.E., Harter, R.D., Tiller, K.G., 1997. Cadmium sorption and transport in variable charge soils: a review. Journal of Environmental Quality 26, 602-617.

Randall, S.R., Sherman, D.M., Ragnersdottir, K.V., Collins, C.R., 1999. The mechanism of cadmium surface complexation on iron oxyhydroxide minerals. Geochimica et Cosmochimica Acta 63, 2971-2987.

Sakurai, K., Ohdate, Y., Kyuma, K., 1989. Potentiometric automatic titration method to evaluate zero point of charge of variable charge soils. Soil Science and Plant Nutrition 35, 89-100.

Schindler, P.W., Liechti, P., Westall, J.C., 1987. Adsorption of copper, cadmium and lead from aqueous solution to the kaolinite/water interface. Netherlands Journal of Agricultural Science 35, 219-230.

Schmitt, H.W., Sticher, H., 1991. Heavy metal compounds in the soil. In: Merian, E. (Ed.), Metals and Their Compounds in the Environment. VCH Verlagsgessellschaft, Weinheim, pp. 311-326.

Schultz, M.F., Benjamin, M.M., Ferguson, J.F., 1987. Adsorption and desorption of metals on ferrihydrite: reversibility of the reaction and sorption properties of the regenerated solid. Environmental Science \& Technology 21, 863-869.

Shiowatana, J., Tantidanai, N., Nookabkaew, S., Nacapricha, D., 2001. A novel continuous-flow sequential extraction procedure for metal speciation. Journal of Environmental Quality 30, 1195-1205.

Shirvani, M., Kalbasi, M., Shariatmadari, H., Nourbakhsh, F., Najafi, B., 2006. Sorption-desorption of cadmium in aqueous palygorskite, sepiolite, and calcite suspensions: isotherm hysteresis. Chemosphere 65, 2178-2184.

Spark, K.M., Johnson, B.B., Wells, J.D., 1995. Characterizing heavy-metal adsorption on oxides and oxyhydroxides. European Journal of Soil Science 46, 621-631.

Sparks, D.L., 1987. Potassium dynamics in soil. Advances in Soil Sciences 6, 1-63.

Sposito, G., 1980. Derivation of the Freundlich equation for ion exchange reactions in soils. Soil Science Society of America Journal 44, 652-654.

Strobel, B.W., Hansen, H.C.B., Borggaard, O.K., Andersen, M.K., Raulund-Rasmussen, K., 2001. Cadmium and copper release kinetics in relation to afforestation of cultivated soil. Geochimica et Cosmochimica Acta 65, 1233-1242.

Taylor, R.W., Hassan, K., Mehadi, A.A., Shuford, J.W., 1995. Kinetics of zinc sorption by soils. Communications in Soil Science and Plant Analysis 26, 1761-1771.

Teng, H., Hsieh, C., 1999. Activation energy for oxygen chemisorption on carbon at low temperatures. Industrial \& Engineering Chemistry Research 38, 292-297.

Wang, W.X., Ding, G.A., 1997. The geographical distribution of ion concentration in precipitation over China. Research of Environmental Sciences 10 (2), 1-7 (in Chinese). 
Xu, R.K., Ji, G.L., 2001. Effects of $\mathrm{H}_{2} \mathrm{SO}_{4}$ and $\mathrm{HNO}_{3}$ on soil acidification and aluminum speciation in variable and constant charge soils. Water, Air, and Soil Pollution 129, 33-43.

Yu, T.R. (Ed.), 1997. Chemistry of Variable Charge Soils. Oxford University Press, New York, pp. 339-367.

Zhang, F.S., Zhang, X.N., Yu, T.R., 1991. Reactions of hydrogen ions with variable charge soils. I. Mechanisms of reaction. Soil Science 151, 436-443.
Zhang, H., Davison, W., Tye, A.Y., Crout, N.M.J., Young, S.D., 2006. Kinetics of zinc and cadmium release in freshly contaminated soils measured by DGT and isotopic dilution. Environmental Toxicology and Chemistry 25, 664670.

Zhu, M.X., Jiang, X., Ji, G.L., 2005. Investigation of time-dependent reactions of $\mathrm{H}^{+}$ ions with variable and constant charge soils: a comparative study. Applied Geochemistry 20, 169-178. 